\title{
The Use of Virtual Environments in Geoscience Education
}

\author{
Hana Švedováa, *, Petr Kubíček ${ }^{\mathrm{a}}$ \\ a Department of Geography, Faculty of Science, Masaryk University, Brno, Czechia, svedova.hana@mail.muni.cz, \\ kubicek@geogr.muni.cz \\ * Corresponding author
}

Keywords: Virtual Reality, Virtual Environment, Education, Geoscience, Immersion, Interactivity, Learning Style

\begin{abstract}
:
The progress of virtual reality (VR), especially over the last decade or two, has been enormous in many domains, and researchers have studied the use of VR in education, training, and simulating scenarios. Virtual reality is a great tool to present phenomena challenging to perform in real-world conditions or to explain in a traditional way of teaching. Geoscience - the study of Earth, is full of topics that could benefit from virtual reality characteristics to assist the learning process and make it engaging and effective. Additionally, user-friendly VR tools (headsets or mobile VR) are accessible to a broader audience than ever in the past due to relatively recent VR development.
\end{abstract}

Virtual reality is broadly defined as a computer-generated environment where users can interact with artificial stimuli in a seemingly natural or physical way by using specific hardware. To understand its benefits for education, educators need to be aware of the aspects that make it advantageous and appealing. Concannon et al. (2019) present immersion, interactivity, and imagination as three basic VR features. The level of immersion is defined by the degree to which a user is either physically or mentally embraced in a virtual environment (Rebelo et al., 2012). Interactivity is the responsiveness and accuracy of user actions when manipulating input hardware (Rebelo et al., 2012). Finally, imagination comes from a user's awareness and belief of being in a virtual environment, despite knowing of being physically in a real environment (Burdea \& Coifert, 2003). Various VR setups emphasize those three features differently to achieve the desired goals and outputs.

Existing research implies VR is effective on multiple education levels, and students prefer VR to other forms of passive learning (Shakirova et al., 2020; Šašinka et al., 2019; Huang et al., 2010). However, Huang et al. (2010) or Mikropoulos \& Natsis (2011) claim that it is necessary to lean on a solid pedagogical baseline to begin with every educational innovation. The use of virtual reality in education is aligned with the approach of constructivism - a learning paradigm claiming humans generate meaning through active, constructive processes (Kavanagh et al., 2017, Huang et al., 2010). Allcoat \& von Mühlenen (2018) point out that the use of educational VR might also depend on learning style. They mention in their study a well-documented visual-auditory-kinaesthetic learning style model (Barbe et al., 1988). The model involves three types of learning (visual, auditory, kinaesthetic) that can all be embraced in a virtual environment. Another strong pedagogical motivation for using VR is the possibility of collaboration and gamification features. Collaboration appears to be a common motivator in many systematic review studies regarding VR education (Kavanagh et al., 2017). Gamification features increase student's engagement and enjoyment from the learning experience.

Furthermore, it is essential to be familiar with the educational subject field's rationale and differentiate situations where virtual reality brings benefit to more thorough understanding, retention, and engagement and where its benefits are negligible. Not every learning method is suitable for every subject - remembering is better for learning fundamental and specific facts than developing analytical thinking. Accordingly, VR is not equally convenient for every educational field. Its significant advantages addressing educational subject choice are enhanced 3D visualization and the possibility of efficiently demonstrating temporal data. Preference of virtual reality to passive visualization by video is due to a higher level of immersion and interactivity. Therefore, VR might not be as beneficial for learning handcrafts or playing the piano but is much more helpful for dynamic spatio-temporal topics. Geoscience often deals with passive, frontal teaching limits regarding geospatial phenomena and concepts (hypsography, map projections, geomorphological processes, altitudinal pressure change, socioeconomic changes in time, etc.). Those topics can be difficult to imagine only based on 2D figures, and thus student's understanding and engagement decrease. Those could be more effectively demonstrated by different meanings, for example, virtual environments providing immersive and interactive ways of presenting curriculum content to students. In addition, VR can provide visual, audio, or even haptic feedback valuable for education and active learning.

Creating a suitable virtual environment can be very costly, demanding, and time-consuming. Despite many studies and research regarding its use not only in Geoscience (e. g. Stojšić et al., 2017), the success of educational VR is not entirely guaranteed yet, and it is still necessary to investigate its potential usefulness for learning. Apart from applied research, there is also a need to identify Geoscience topics that would benefit from virtual environments and compile or at least suggest theoretical background for teaching Geoscience with the help of virtual reality anchored in solid pedagogy and methodology. 
The proposed research addresses the issues of gaps in VR education in Geoscience and suitable visualization. Systematic reviews of VR in education published so far have focused mainly on education in general. Therefore, the initial part of the research is the current compiling of a systematic review of the use and potential of virtual reality in higher Geoscience education. In parallel, we have performed an exploratory study with the following partial results significant for future research:

- The user's expectation of virtual educational environments was far beyond the setting of an experiment. Higher demands of VR engagement were probably partially caused by previous user's experience with VR in the entertainment industry. Therefore, it is necessary to apply other beneficial characteristics of VR to retain engagement and concentration (interactivity, gamification, collaboration, etc.). This assumption was confirmed by the geography teachers as well.

- Regarding Geography, it is crucial to carefully choose topics (for example, with cooperation with school teachers) that can be beneficial for teaching in VR. At the same time, the visualization elements and the complexity of sensory inputs in virtual environments should be appropriate for their purpose and should not overwhelm the students. Furthermore, selected topics matching school curricula for their following efficient application are also very suitable.

- Users should sufficiently explore and get used to the virtual environment and learn how to use VR devices before participating in a fully immersive and interactive VR experiment. Lack of familiarity with those causes significant delays and unnecessary differences among participants and their experience.

- During experiments, it is essential to check on participants to provide as much comfort as possible so that their experience does not negatively influence confusion, nausea, or any discomfort caused by VR devices.

The systematic review aims to collect and gather Geoscience and spatial tasks VR experiments, ideally performed in a fully immersive virtual environment. Those research findings will help us identify potential gaps and opportunities in following basic and applied research. Study selection and the whole review report will be guided by the principles of the PRISMA statement and the review guide conducted by Kitchenham et al. (2007). The focus of basic research is going to be on expanding knowledge about educational approaches, methodology, and pedagogical baseline with the use of virtual environments. After the initial results of the systematic review, we plan to verify the outputs of existing research and systematic review and identify some of the Geoscience fields where the VR can be beneficial compared to standard frontal teaching or even learning outdoors. Based on the literature research, systematic review, and expert evaluation (didactic experts, geography teachers), we aim to design, create, and perform experiments with students in fully immersive and interactive virtual educational environments with appropriate Geoscience tasks. We believe those findings might help contribute to creating a more effective and helpful framework for the use of virtual reality in learning and teaching Geoscience.

\section{References}

Allcoat, D., \& von Mühlenen (2018). Learning in virtual reality: Effects on performance, emotion and engagement. A Research in Learning Technology, 26. http://dx.doi.org/10.25304/rlt.v26.2140

Barbe, W., Milone, M., \& Swassing, R. (1988). Teaching through Modality Strengths, ZanerBloser, Columbus, OH.

Burdea, G. C., \& Coiffet, P. (2003). Virtual Reality Technology. Hoboken, NJ: JohnWiley and Sons.

Concannon, B. J., Esmail, S., \& Roduta Roberts, M. (2019). Head-mounted display virtual reality in post-secondary education and skill training. Frontiers in Education, 4. doi:10.3389/feduc.2019.00080

Huang, H.-M., Rauch, U., \& Liaw, S.-S. (2010). Investigating learners' attitudes toward virtual reality learning environments: Based on a constructivist approach. Computers \& Education, 55(3), 1171-1182.

Kavanagh, S., Luxton-Reilly, A., Wuensche, B., \& Plimmer, B (2017). A systematic review of Virtual Reality in education. Themes in Science \& Technology Education, 10(2), 85-119.

Mikropoulos, T., \& Natsis, A. (2011). Educational Virtual Environments: A Ten-Year Review of Empirical Research (1999-2009). Computers \& Education, 56, 769-780. http://dx.doi.org/10.1016/j.compedu.2010.10.020

Rebelo, F., Noriega, P., Duarte, E., \& Soares, M. (2012). Using virtual reality to assess user experience. Human Factors, 54(6), 964-982. doi:10.1177/0018720812465006

Shakirova, N., Al Said, N., \& Konyushenko, S. (2020). The use of virtual reality in geo-education. International Journal of Emerging Technologies in Learning, 15(20), 59-70. doi:10.3991/ijet.v15i20.15433

Stojšić, I., Ivkov Džigurski, A., Maričić, O., Ivanović Bibić, L., \& Đukičin Vučković, S. (2017). Possible Application of Virtual Reality in Geography Teaching. Journal of Subject Didactics, 1(2), 83-96. 
Šašinka, C., Stachoň, Z., Sedlák, M., Chmelík, J., Herman, L., Kubíček, P., . . Juřík, V. (2019). Collaborative immersive virtual environments for education in geography. ISPRS International Journal of Geo-Information, 8(1). doi:10.3390/ijgi8010003 